\title{
Synthesis and Characterization of Crosslinked Hydrogel of Konkoli (Maesopsis eminii) Grafted Polymethylacrylamide for a Preliminary Study as an Insulin Delivery System
}

\author{
Okoko Barth Ugwu, Jeffery T. Barminas, Iliya I. Nkafamiya, Ayodele Akinterinwa* \\ Modibbo Adma University of Technology, Yola, Nigeria \\ Email: *ayoterinwa@yahoo.com
}

How to cite this paper: Ugwu, O.B., Barminas, J.T., Nkafamiya, I.I. and Akinterinwa, A. (2016) Synthesis and Characterization of Crosslinked Hydrogel of Konkoli (Maesopsis eminii) Grafted Polymethylacrylamide for a Preliminary Study as an Insulin Delivery System. Journal of Biosciences and Medicines, 4, 36-47. http://dx.doi.org/10.4236/jbm.2016.411005

Received: July 12, 2016

Accepted: November 20, 2016

Published: November 24, 2016

Copyright $\odot 2016$ by authors and Scientific Research Publishing Inc. This work is licensed under the Creative Commons Attribution International License (CC BY 4.0). http://creativecommons.org/licenses/by/4.0/ (c) (i) Open Access

\section{Abstract}

Polysaccharide has lately received a significant attention in the formulation of drug delivery system based on the abundant availability, non-toxicity and the various ways its nature, structure and functionality can be modified. In this preliminary work on Konkoli (Maesopsis eminii) galactomannan (KG), it was modified by grafting with methacrylamide (MAAm) using ammonium persulphate (ASP) as initiator. The grafted galactomannan was then crosslinked using $\mathrm{N}, \mathrm{N}$-methylenebisacrylamide $(\mathrm{N}$, N-MBAAm) to produce the hydrogel called konkoli grafted polymethylacrylamide (KG-g-poly (MAAm)). FTIR analyses confirm crosslinking and other changes in the functionality of KG-g-poly (MAAm) compared to KG. Swelling properties which are fundamental to the potential properties of any hydrogel as a drug delivery system were studied for KG-g-poly (MAAm) with varied amount of monomer (MAAm), crosslinker and $\mathrm{pH}$ with respect to time and temperature. There was a rapid rise followed by a dramatic fall in the swelling capacity with increase in both monomer and crosslinker concentration. The swelling capacity of KG-g-poly (MAAm) also improves as the $\mathrm{pH}$ of the medium was changed from acidic to alkaline. Generally, the swelling capacity of KG-g-poly (MAAm) increases with time and temperature of immersion. This result therefore encourages further studies as it presents KG-g-poly (MAAm) potentials in such application as insulin delivery system.

\section{Keywords}

Konkoli (Maesopsis eminii) Galactomannan, Hydrogels, Konkoli Grafted Polymethylacrylamide (KG-g-poly (MAAm)), Swelling Properties 


\section{Introduction}

Diabetes mellitus is a group of metabolic diseases characterized by high blood sugar (glucose) levels that result from defects in insulin secretion, or action, or both [1]. It is a chronic medical condition which even though can be controlled, may last a lifetime [1] [2]. Blood glucose level is controlled by insulin, a hormone produced by the pancreas. In patients with diabetes, the absence or insufficient production of insulin causes hyperglycemia and other physiological failure as blindness, kidney failure, nerve damage and blood vessel diseases leading to strokes and coronary heart disease [1] [3]. To enhance the supply of insulin to such patient by administration therefore, a gradual and consistent means is the resort.

Needle is the pioneer means of administration. The problem of drug concentrations oscillation, and short half-life, which necessitates multiple injections within short intervals of time causing compliance issues, especially when long-term treatment is required as in the treatment of diabetes mellitus by insulin, quest the elimination of injection in insulin delivery [4]. Recently, various approaches have been studied involving many strategies using various technologies showing successes in delivering insulin, which are designed to overcome the inherent barriers for insulin uptake across the gastrointestinal tract, mucosal membrane and skin [4] [5] [6].

Hydrogels are materials that can swell quickly by imbibing a large amount of water, a behavior that can be influenced by some changes in their external environment [7] [8]. The volume phase transitions as a response to different stimuli such as; $\mathrm{pH}$, temperature, ionic strength and electro stimulus, makes these materials interesting objects of scientific observations and useful materials for use in advanced technologies [7] [8] [9] [10].

The development of novel materials in controlled drug delivery is focused on the preparation and use of responsive polymers with specifically designed macroscopic and microscopic structural and chemical features, a group into which hydrogels fits [4]. Such systems include different forms and modifications of polymeric materials, an example of which is the carbohydrate-based polymers, technologically tailored by researchers who envision their use not only for innovative drug delivery systems but also as potential linings for artificial organs, as substrates for cell growth or chemical reactors, as agents in drug targeting and immunology testing, as biomedical adhesives and bioseparation membranes, and as substances able to mimic biological systems [4] [11] [12].

Some systems under study for insulin delivery base their delivery on the reaction of glucose in the blood with glucose oxidase [4]. These immobilize on polymers within the drug delivery system and the glucose/glucose oxidase reaction causes a lowering of the $\mathrm{pH}$ in the delivery system's microenvironment [13]. This can cause an increase in the swelling of the polymer system, leading to an increased release of insulin, for delivery systems that are based on copolymers containing N, N-dimethylaminoethyl methacrylate as far reported by Kost et al. [14] and polyacrylamide by Ishihara et al. [15]. Early work with biodegradable polymers has also yielded polyorthoesters that are $\mathrm{pH}$ sensitive and that will degrade more quickly in acidic environments [16]. Such polymers have been studied as the central core of a drug delivery system in which the polymer- 
insulin matrix is surrounded by a membrane containing grafted glucose oxidase, which provides the reaction substrate and the change in $\mathrm{pH}$ necessary to enhance biodegradation and subsequent insulin delivery. Another inventive system uses polymers that will shrink rather than swell at low $\mathrm{pH}$ values. These are called molecular gates systems that feature as insulin-containing reservoirs with a delivery-rate-controlling membrane of poly (methacrylic acid-g-poly (ethylene glycol)) copolymer in which glucose oxidase has been immobilized [17]. These gels expand at high $\mathrm{pH}$ values (normal body $\mathrm{pH}$ of 7.4), closing the gates, and shrinks at low $\mathrm{pH}$ values ( $\mathrm{pH}$ of approximately 4.0 due to interaction of glucose with immobilized glucose oxidase), opening the gates [9]. Control of the insulin delivery depends on the size of the gates, the concentration of insulin, and the rate of the gates' opening or closing, i.e., response rate [18]. As investigated while monitoring the plasma glucose level of alloxan-induced diabetic rats after oral administration of various doses of insulin-loaded chitosan-nanoparticles, polysaccharides based hydrogels has also reportedly made a good delivery system [4] [12] [19].

Konkoli (Maesopsis eminii) galactomannan has been exhaustively described by Barminas [20]. It is a polysaccharide, locally available, and with some properties that makes it suitable as hydrogel for drug delivery system [20]. This work therefore begins a preliminary investigation into the modification and analysis of this material in a quest towards its potential application as an oral insulin delivery system.

\section{Materials and Method}

\subsection{Materials}

Konkoli (Maesopsis eminii) galactomannan was obtained from Baisa in Taraba State, Nigeria. Methacrylamide (MAAm), sodium hydroxide, hydrochloric acid, potassium chloride, dihydrogen potassium phosphate, sodium potassium tartrate and Folin's reagents are products of Merck-Schuchardt, Germany. Ammonium persulphate (APS), copper sulphate and N, N'-methylenebisacrylamide (N, N-MBAAm) obtained from S.D. Fine Ltd, sodium carbonate is Ranbaxy product, while insulin was obtained from Torrent Pharmaceuticals Ltd.

\subsection{Synthesis of Hydrogels}

The crosslinked KG-g-poly (MAAm) was synthesized using the procedure reported by Osemeahon et al. [21] as modified using the method reported by Singh and Sharma [22]. According to this method, $1 \mathrm{~g}$ of konkoli (KG) was introduced into $1.095 \times 10^{-2}$ moles/L solution of APS. MAAm $(0.135 \mathrm{~mol} / \mathrm{l})$ and N, N-MBAAm $\left(1.62 \times 10^{-2} \mathrm{~mol} / \mathrm{l}\right)$ was again added, before the aqueous system was set at $65^{\circ} \mathrm{C}$ for $2 \mathrm{~h}$. The polymers thus formed were stirred for $2 \mathrm{~h}$ in distilled water and again $2 \mathrm{~h}$ in ethanol to remove the soluble fractions of the polymer and then dried in an air oven at $40^{\circ} \mathrm{C}$.

\subsection{Characterization of Hydrogels}

The pure konkoli galactomannan and the synthesized hydrogels were characterized us- 
ing Fourier transform infrared spectroscopy (FTIR) and by investigating the swelling behaviors.

\subsection{Fourier Transforms Infrared (FTIR) Spectroscopy}

FTIR analysis was carried out using a Perkin Elmer (Model Impact 410, Wisconsin, USA) spectrophotometer. The dried samples of konkoli and hydrogels were finely ground with $\mathrm{KBr}$ pellets under a hydraulic pressure of $400 \mathrm{~kg}$ and spectra obtained by scanning between 4000 and $400 \mathrm{~cm}^{-1}$.

\subsection{Swelling Measurements}

Swelling studies of the materials were carried out in aqueous medium by gravimetric method [22]. Known weight $\left(\mathrm{W}_{\mathrm{d}}\right)$ of dry hydrogels $(0.10 \mathrm{~g})$ were taken and immersed in distilled water. The swollen polymer was then separated from the water on a $100 \mu \mathrm{m}$ mesh after the stipulated time of investigation, and weighed $\left(\mathrm{W}_{\mathrm{s}}\right)$. The swelling capacity (in percent) was then calculated from;

$$
\left[\left(\mathrm{W}_{\mathrm{s}}-\mathrm{W}_{\mathrm{d}}\right) / \mathrm{W}_{\mathrm{d}}\right] \times 100
$$

where $\mathrm{W}_{\mathrm{d}}$ and $\mathrm{W}_{\mathrm{s}}$ represent the dry and swollen hydrogel weight respectively.

\subsection{Determination of the Effect of Monomer Concentration on Swelling with Time}

The synthesis was repeated while keeping all other initial conditions constant and varying the amount of MAAm ( 0.135 to $0.725 \mathrm{~mol} / \mathrm{l})$. Products obtained were then subjected to swelling investigation at different times of immersion (10 min, $30 \mathrm{~min}, 1 \mathrm{~h}, 2$ $\mathrm{h}$, and $24 \mathrm{~h}$ ), and at media temperature of $40^{\circ} \mathrm{C}$.

\subsection{Determination of the Effect of Crosslinker Concentration on Swelling with Time}

The synthesis was repeated while keeping all other initial conditions constant and varying the amount of crosslinker i.e. N, N-MBAAm $\left(1.62 \times 10^{-2}\right.$ to $\left.32.40 \mathrm{~mol} / \mathrm{l}\right)$.Products obtained were then subjected to swelling investigation at different times of immersion (10 min, $30 \mathrm{~min}, 1 \mathrm{~h}, 2 \mathrm{~h}$, and $24 \mathrm{~h}$ ), and at media temperature of $40^{\circ} \mathrm{C}$.

\subsection{Determination of the Effect of Monomer Concentration on Swelling with Temperature}

The synthesis was repeated while keeping all other initial conditions constant and varying the amount of MAAm ( 0.135 to $0.725 \mathrm{~mol} / \mathrm{l})$. Products obtained were then subjected to swelling investigation at different temperatures of the immersion medium $\left(30^{\circ} \mathrm{C}, 35^{\circ} \mathrm{C}, 40^{\circ} \mathrm{C}\right.$ and $\left.45^{\circ} \mathrm{C}\right)$, for $2 \mathrm{~h}$.

\subsection{Determination of the Effect of Crosslinker Concentration on Swelling with Temperature}

The synthesis was repeated while keeping all other initial conditions constant and va- 
rying the amount of crosslinker i.e. N, N-MBAAm $\left(1.62 \times 10^{-2}\right.$ to $\left.32.40 \mathrm{~mol} / \mathrm{l}\right)$. Products obtained were then subjected to swelling investigation at different temperature of the immersion medium $\left(30^{\circ} \mathrm{C}, 35^{\circ} \mathrm{C}, 40^{\circ} \mathrm{C}\right.$ and $\left.45^{\circ} \mathrm{C}\right)$, for $2 \mathrm{~h}$.

\subsection{Determination of the Effect of Media pH on Swelling with Time}

The synthesized hydrogel was subjected to swelling at $30^{\circ} \mathrm{C}$ in different media solutions with $\mathrm{pH} \mathrm{4,} 7$ and 9, modulated with $0.5 \mathrm{M} \mathrm{HCl}$ and $0.5 \mathrm{M} \mathrm{NaOH}$. Investigation was carried out at intervals of 10 mins, from 10 - 120 mins.

\section{Result and Discussion}

The polymeric networks were synthesized by chemically induced polymerization through free radical initiated by APS. The APS generated reactive sites on both the konkoli and monomer (MAAm). The crosslinker (N, N-MBAAm) is a poly-functionality crosslinker that has four reactive sites. These sites can be linked with the radicals on the galactomannan and the poly (MAAm). This therefore afford the three-dimensional networks in the hydrogels obtained and designated as konkoli-grafted-polyacry-lamide (KG-gpoly(MAAm) [21]. The overall chemical reaction is as shown in Scheme 1.
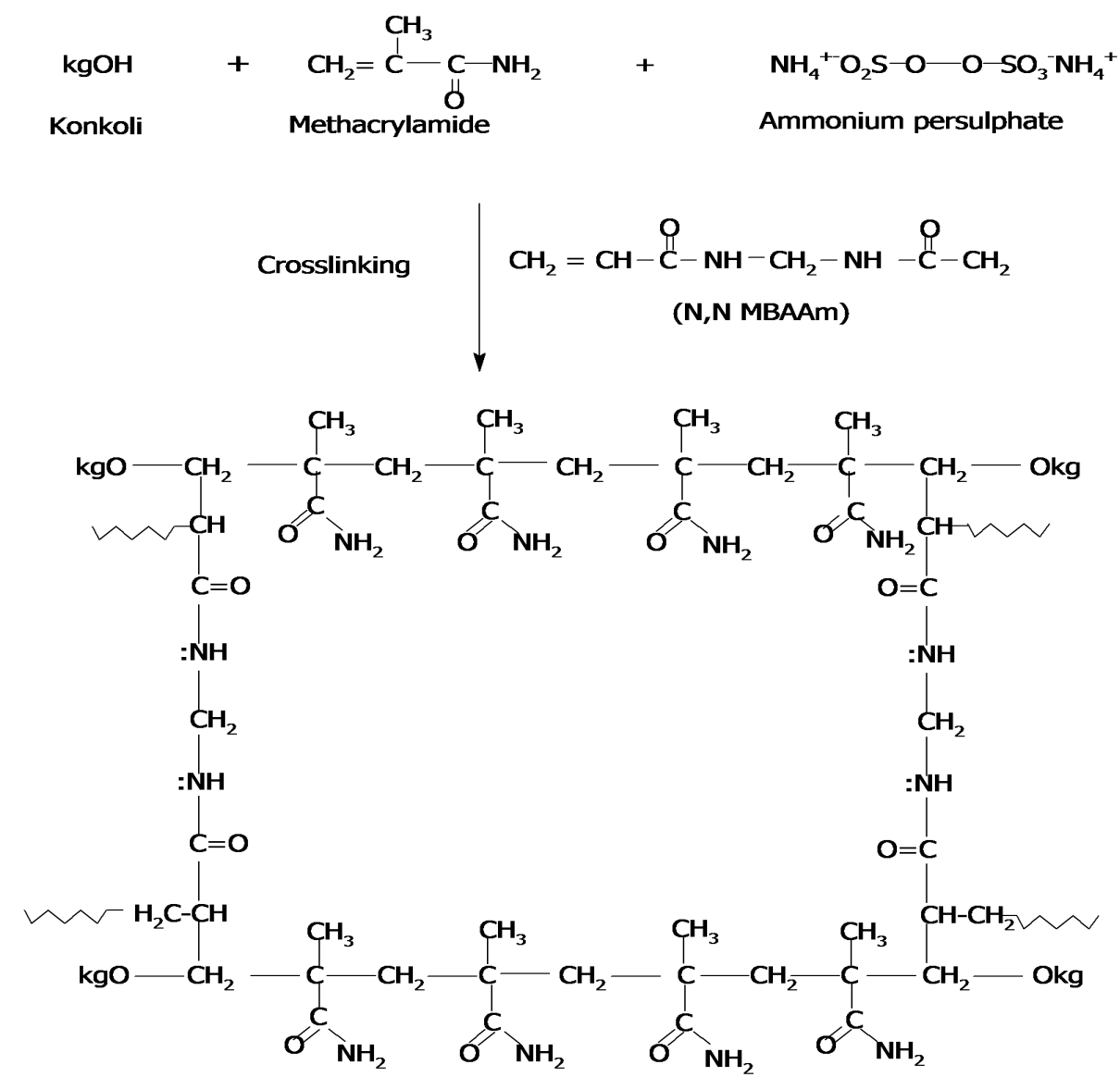

Scheme 1. Konkoli-grafted-polyacrylamide (KG-g-poly (MAAm). Grafting and crosslinking of Konkoli (Maesopsis eminii) galactomannan. 


\subsection{Fourier Transformed Infrared Spectroscopy}

FTIR analysis of both Konkoli Galactomannan and KG-g-poly(MAAm) was carried out to study the modification of the psyllium as shown in Figure 1(a) and Figure 1(b) respectively. The observed broad absorption band at $3405.0 \mathrm{~cm}^{-1}$ and $3427.0 \mathrm{~cm}^{-1}$ on both spectra are due to stretching vibration of $-\mathrm{OH}$ groups on the galactomannan backbone. Bands in the region $1200-1000 \mathrm{~cm}^{-1}$ due to $\mathrm{C}-\mathrm{O}$ and $\mathrm{C}-\mathrm{O}-\mathrm{C}$ stretching vibrations which are the characteristic of the natural polysaccharides have also been observed. FTIR absorption bands due to $\mathrm{C}=\mathrm{O}$ stretching of amide is observed at $1664.5 \mathrm{~cm}^{-1}$ in KG-g-poly (MAAm). The modified konkoli also showed a peak at $1454.3 \mathrm{~cm}^{-1}$ due to the $\mathrm{NH}$ and $\mathrm{CN}$ stretching vibrations. The peaks at $897 \mathrm{~cm}^{-1}$ is due to $\mathrm{NH}$ and $\mathrm{CH}$ out of plane bending of amide of the crosslinked polymer. There is a general decrease in the absorbance intensity in all the peaks of the modified galactomannan common to the natural substance. This therefore shows a reduction per unit mass of the initial functional composition of the natural galactomannan compared to the modified material.

\subsection{Effect of Monomer Concentration on Swelling with Time}

The dependence of the swelling capacity of hydrogels on MAAm concentration with time is illustrated in Figure 2. The swelling capacity generally increased with increase in swelling time. There was an initial increase in swelling capacity with increase in the MAAm concentration followed by a drop at $0.6 \mathrm{~mol} / \mathrm{L}$ concentration of the monomer at all the times of analysis. This may be due to initial availability of monomer molecules

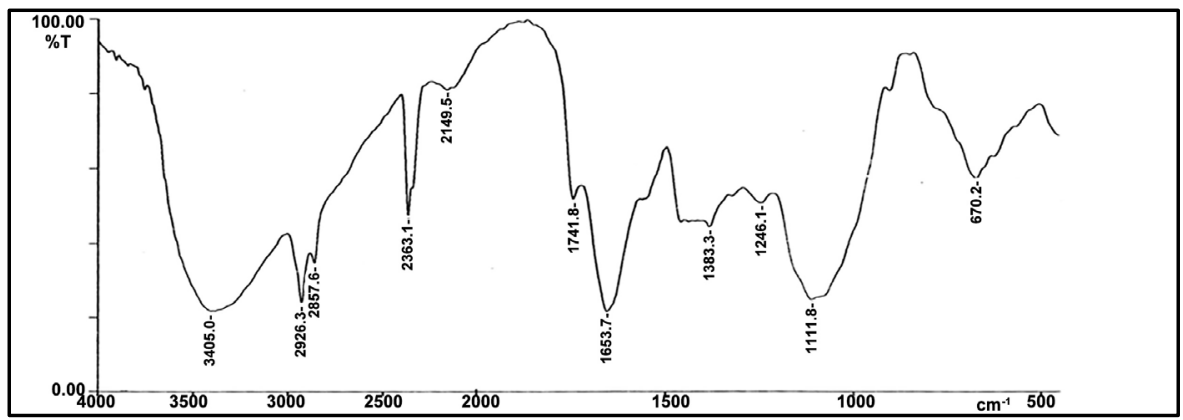

(a)

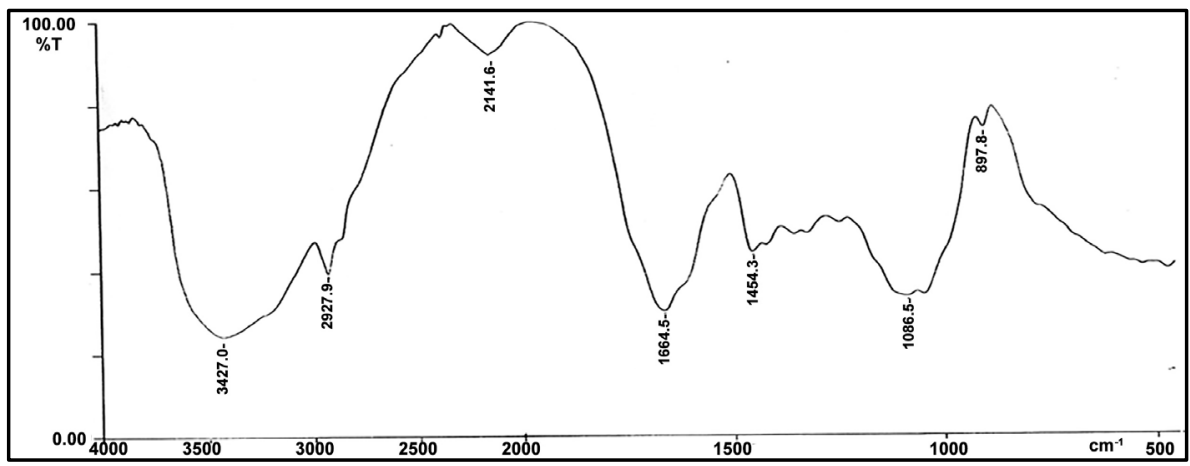

(b)

Figure 1. FTIR Spectra of Konkoli Galactomannan (a) and KG-g-poly (MAAm) (b). 
in the vicinity of the chain propagating sites of chitosan macroradicals. Higher MAAm content enhances the hydrophilicity of the hydrogel in KG-g-MAAm which might cause a stronger affinity for morewater [23]. A further increase in monomer concentration, however, results in decreased water absorbency. This may be due to preferential homopolymerization over graft copolymerization, an increase in the viscosity of the medium, which hinders the movement of free radicals and monomer molecules, the enhanced chance of chain transfer to monomer molecules, andnon-hydrolyzed amide groups of grafted and ungrafted MAAm chains [10] [23].

\subsection{Effect of Crosslinker Concentration on Swelling with Time}

Figure 3 presents the effect of N,N-MBAAm concentration on the water absorbency of the KG-g-MAAm hydrogel with time. Just as observed in Figure 2, swelling capacity increased with increase in immersion time, but decreases with increase in [NNMBAAm] concentration in the networks. This is due to a decrease in the space between the polymer chains as the crosslinker concentration is increased [8]. This decreasing trend is similar to the report by Singh and coworkers for the hydrogels based on psyllium and poly (AAc), and some other reports [7] [10].

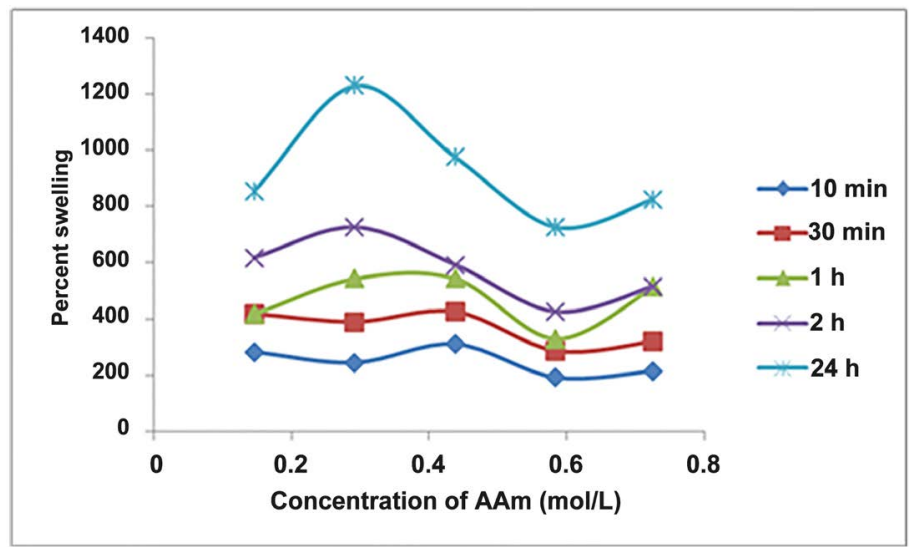

Figure 2. Effect of MAAm concentration on swelling with time.

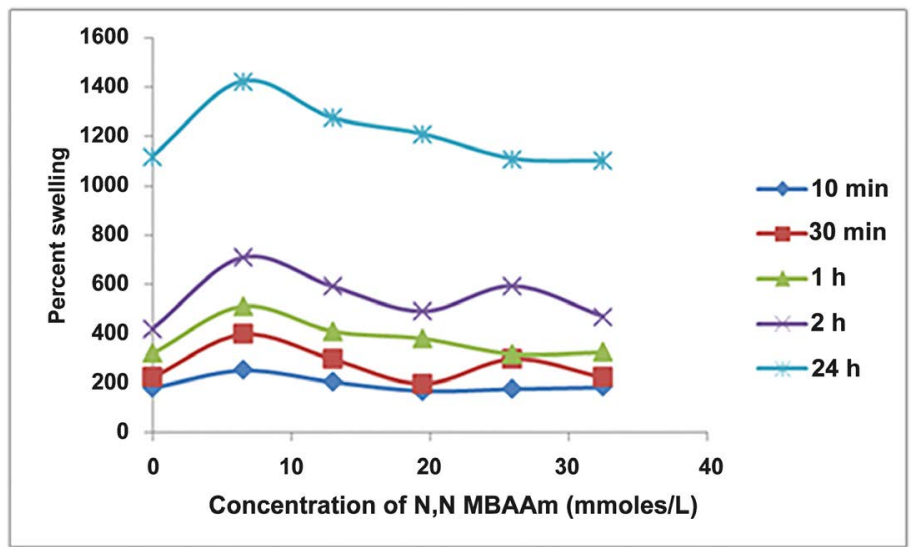

Figure 3. Effect of N,NMBAAm concentration on swelling with time. 


\subsection{Effect of Monomer Concentration on Swelling with Temperature}

As shown in Figure 4, swelling capacity of the KG-g-poly (AAm) increased with increase in temperature for each of the monomer concentration except at $40^{\circ} \mathrm{C}$ and $45^{\circ} \mathrm{C}$ within the monomer concentration range of $0.146 \mathrm{~mol} / \mathrm{L}-0.438 \mathrm{moles} / \mathrm{L}$. This is expected because as temperature is raised in many polymer systems, fewer chain entanglements are present resulting in a fall in viscosity as well as the swelling of the material [7] [10]. At all temperatures, as the concentration of monomer in polymer networks increases, swelling capacity increases to a maximum value and decreases thereafter. This observed decrease could be supported by the fact that incorporation of higher amount of monomer lead to self-crosslinking, hence, prevents accessibility of more solvent in the matrix [7] [10] [24].

\subsection{Effect of Crosslinker Concentration on Swelling with Temperature}

The swelling behavior of the polymer as shown in Figure 5 indicates that the swelling capacity consistently increased with increase in temperature. And this is in agreement with the report by Kim et al. [25]. At all the temperatures, there is a sharp rise in swelling capacity to a maximum peak at $6.45 \mathrm{mmol} / \mathrm{L}$. this is followed by a gradual rise except $35^{\circ} \mathrm{C}$, Son and Lee [8], also discussed a similar phenomenon. This may be due to the following; only a very small concentration of crosslinker might have brought about an abrupt transition from liquid to gel state during the synthesis of hydrogels, the crosslinking density increasing with increase in the crosslinker concentration and the pore size of the crosslinked network [8] [10] [25].

\subsection{Effect of Media pH on Swelling with Time}

Figure 6, presents the results for the swelling behavior of hydrogel in different $\mathrm{pH}$ media. The swelling capacity of hydrogel increased as the $\mathrm{pH}$ changed from acidic to alkaline. This is meritorious as it will compensate for the $\mathrm{pH}$ reduction by a possible glucose/glucose oxidase reaction [13]. This effect can be attributed to the presence of different interacting species depending on the $\mathrm{pH}$ of the swelling medium. At alkaline $\mathrm{pH}$

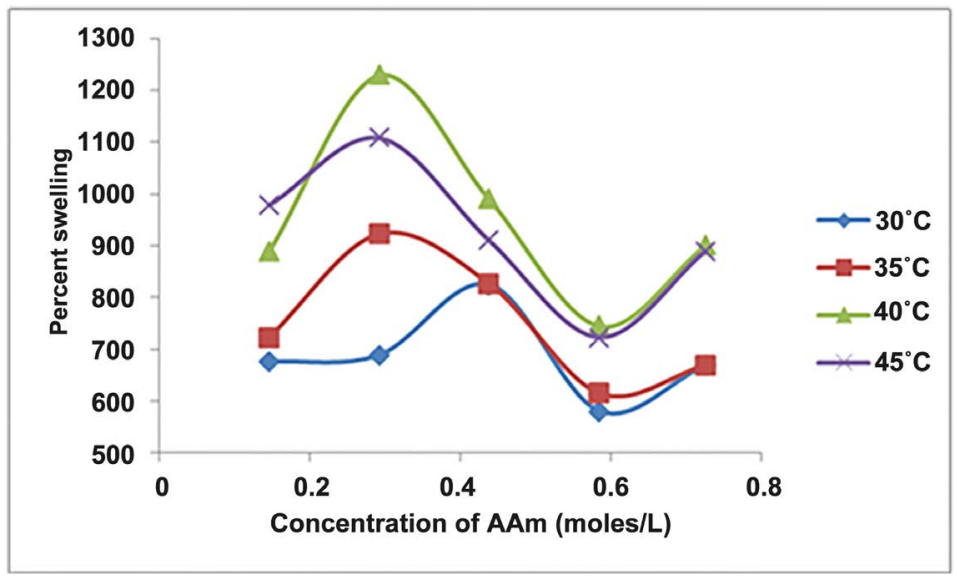

Figure 4. Effect of MAAm concentration on swelling with temperature. 


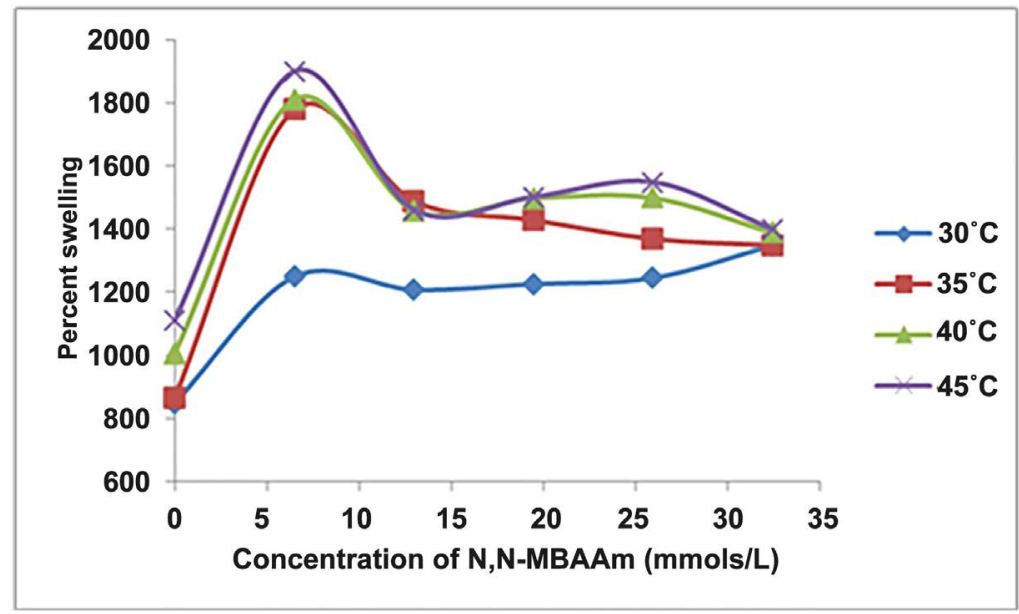

Figure 5. Effect of N,NMBAAm concentration on swelling with temperature.

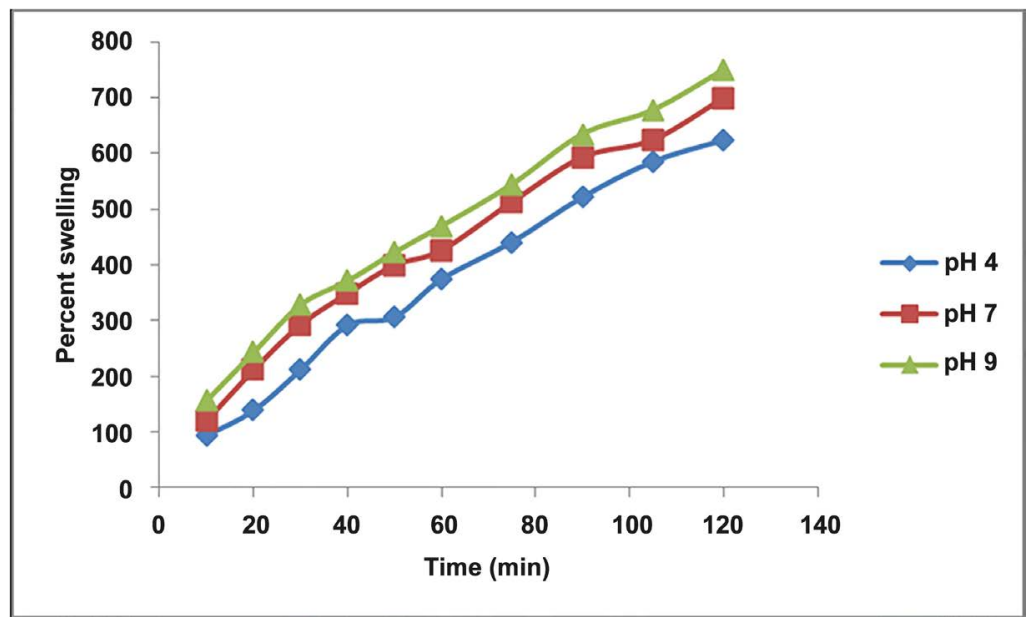

Figure 6. Effect of media $\mathrm{pH}$ on swelling with time.

$(\mathrm{pH} 9)$, the $-\mathrm{COOH}$ groups are ionized and $-\mathrm{CONH}-$ and $-\mathrm{CONH}_{2}$ groups are deprotonated. These charged $\mathrm{COO}-$ and deprotonated amide groups cause electrostatic repulsion forces. Both the repulsion of the negatively charged polymer chains and the presence of free counterions $\left(\mathrm{Na}^{+}\right)$in the gel, which cause a high osmotic swelling pressure, could contribute to increased swelling [23]. At lower $\mathrm{pH}$ values, the functional groups of the polymer are protonated (i.e., the $-\mathrm{CONH}_{2}$ groups do not ionize) and keep the network at its collapsed state which causes a decrease in swelling. Under acidic conditions, the swelling is controlled mainly by the amino group $\left(\mathrm{NH}_{2}\right)$ of the polymer. It is a weak base that gets protonated, increased the charge density on the polymer and enhances the osmotic pressure inside the gel particles because of the $\mathrm{NH}^{+3}-\mathrm{NH}^{+3}$ electrostatic repulsion. This osmotic pressure difference between the internal and external solution of the network is balanced by the swelling of the gel. However, a screening effect of the counterion, i.e. $\mathrm{Cl}^{-}$, shields the charge of the ammonium cations and prevents an efficient repulsion. As a result, a remarkable decrease in equilibrium swelling is observed, i.e., gel collapsing [23]. At pH 4 - 7, the carboxylic acid component comes 
into action as well. The majority of the base and acid groups are as $\mathrm{NH}^{+3}$ and $\mathrm{COO}^{-}$or $\mathrm{NH}_{2}$ and $-\mathrm{COOH}$ forms, and therefore ionic interaction of $\mathrm{NH}^{+3}$ and $\mathrm{COO}^{-}$species (ionic crosslinking) or hydrogen bonding between amine and carboxylic acid may lead to a kind of crosslinking followed by decreased swelling, similar behavior was made by Clara et al., [24] for hydrogels of poly (2-acrylamido-2-methyl-1-propanesulfonic acid-co-methacrylic acid). This after all presents KG-g-poly (MAAm) as a $\mathrm{pH}$ sensitive hydrogel.

\section{Conclusion}

As a potential drug delivery system, KG-g-poly (MAAm) in this work show improved structural and functional properties compared to the KG as confirmed by the FTIR analysis. Its preliminary studies for swelling behavior generally show that its swelling capacity increases with increase in time and temperature at optimum monomer and crosslinker concentrations. KG-g-poly (MAAm) is also pH sensitive which is a promising property it this preliminary study. The results from this study show the potentials of KG-g-poly (MAAm) as an insulin delivery system, and this will appreciate further studies.

\section{References}

[1] Deshmukh, C.D. and Jain, A. (2015) Diabetes Mellitus: A Review. International Journal of Pure \& Applied Bioscience, 3, 224-230.

[2] Rother, K.I. (2007) Diabetes Treatment-Bridging the Divide. New England Journal of Medicine, 356, 1499-1501. https://doi.org/10.1056/NEJMp078030

[3] Tierney, L.M, McPhee, S.J. and Papadakis, M.A. (2002) Current Medical Diagnosis \& Treatment. International Edition. Lange Medical Books/McGraw-Hill, New York, 12031215.

[4] Ganguly, K., Chaturvedi, K., More, U.A., Nadagouda, M.N. and Minabhavi, T.M. (2014) Polysaccharide-Based Micro/Nanohydrogels for Delivering Macromolecular Therapeutics. Journal of Controlled Release, 193, 162-173. https://doi.org/10.1016/j.jconrel.2014.05.014

[5] Owens, D.R. (2002) New Horizons-Alternative Routes for Insulin Therapy. Nature Review. Drug Discovery, 1, 529-540. https://doi.org/10.1038/nrd836

[6] Cefalu, W.T. (2004) Concept, Strategies and Feasibility of Non-Invasive Insulin Delivery. Diabetes Care, 27, 239-246. https://doi.org/10.2337/diacare.27.1.239

[7] Singh, B., Chauhan, G.S., Kumar, S. and Chauhan, N. (2007) Synthesis, Characterization and Swelling Responses of $\mathrm{pH}$ Sensitive Psyllium and Polyacrylamide Basedhydrogels for the Use in Drug Delivery (I). Carbohydrate Polymer, 67, 190-200. https://doi.org/10.1016/j.carbpol.2006.05.006

[8] Son, K.H. and Lee, J.W. (2016) Synthesis and Characterization of Poly(Ethylene Glycol) Based Thermo-Responsive Hydrogels for Cell Sheet Engineering. Materials, 9, 854. https://doi.org/10.3390/ma9100854

[9] Zhao, W., Jin, X., Cong, X., Liu, Y. and Fu, J. (2013) Degradable Natural Polymer Hydrogels for Articular Cartilage Tissue Engineering. Journal of Chemical Technology \& Biotechnology, 88, 327-339. https://doi.org/10.1002/jctb.3970

[10] Gökçeören, A.T., Şenkal, B.F. and Erbil, C. (2014) Effect of Crosslinker Structure and Cros- 
slinker/Monomer Ratio on Network Parameters and Thermodynamic Properties of Poly (N-isopropylacrylamide) Hydrogels. Journal of Polymer Research, 21, 1-12.

https://doi.org/10.1007/s10965-014-0370-2

[11] Brannon-Peppas, L. (1997) Biomaterials: Polymers in Controlled Drug Delivery, Medical Plastics and Biomaterials Magazine. www.m.mddionline.com

[12] Giammanco, G.E., Carrion, B., Coleman, R.M. and Ostrowski, A.D. (2016) Photoresponsive Polysaccharide-Based Hydrogels with Tunable Mechanical Properties for Cartilage Tissue Engineering. ACS Applied Materials \& Interfaces, 8, 14423-14429. https://doi.org/10.1021/acsami.6b03834

[13] Mao S., Sun, W. and Kissel, T. (2010) Chitosan-Based Formulations for Delivery of DNA and siRNA. Advanced Drug Delivery Reviews, 62, 12-27.

https://doi.org/10.1016/j.addr.2009.08.004

[14] Kost, J., Horbett, T.A. and Ratner, B.D. (1985) Glucose-Sensitive Membranes Containing Glucose Oxidase: Activity, Swelling, and Permeability Studies. Journal of Biomedical Material Research, 19, 1117-1133. https://doi.org/10.1002/jbm.820190920

[15] Ishihara, K., Kobayashi, M., and Shinohara, I. (1983) Control of Insulin Permeation through a Polymer Membrane with Responsive Function for Glucose. Makromolecules and Chemical Rapid Communication, 4, 327-338. https://doi.org/10.1002/marc.1983.030040511

[16] Heller, J., Pangburn, S.H. and Penhale, D.W.H. (1987) Use of Bioerodible Polymers in Self-Regulated Drug Delivery Systems, In: Lee, P.I. and Good, W.R., Eds., Controlled-Release Technology, Pharmaceutical Applications, Washington DC, ACS Symposium Series, 172-187. https://doi.org/10.1021/bk-1987-0348.ch013

[17] Kim, S.W. (1996) Temperature Sensitive Polymers for Delivery of Macromolecular Drugs, In: Ogata, N., Kim, S.W. and Feijen, J., Eds., Advanced Biomaterials in Biomedical Engineering and Drug Delivery Systems, Springer, Tokyo, 126-133. https://doi.org/10.1007/978-4-431-65883-2_25

[18] Dorski, C.M., Doyle, F.J. and Peppas, N.A. (1997) Preparation and Characterization of Glucose-Sensitive P(MAA-g-EG) Hydrogels. Polymer Materials Science Engineering Proceedings, 76, 281-282.

[19] Pan, Y., Li, Y., Zhao, H., Zheng, J., Xu, H., Wei, G., Hao, J. and Cui, F. (2002) Bioadhesive Polysaccharide in Protein Delivery System: Chitosan Nanoparticles Improve the Intestinal Absorption of Insulin in Vivo. International Journal Pharmaceutics, 249, 139-147. https://doi.org/10.1016/S0378-5173(02)00486-6

[20] Barminas, J.T. (2004) Some Studies on Solution Behaviour of Konkoli (Maesopsis eminii) Seed Gum. Ph.D. Thesis, Federal University of Technology Yola, Nigeria.

[21] Osemeahon, S.A., Barminas, J.T., Aliyu, B.A. and Nkafamiya, I.I. (2008) Development of Sodium Alginate and Konkoli Gum-Graft-Polyacrylamide Blend Membrane Optimization of Grafting Conditions. African Journal of Biotechnology, 7, 1309-1313.

[22] Singh, B. and Sharma, N. (2009) Modification of Psyllium Polysaccharides for Use in Oral Insulin Delivery. Food Hydrocolloids, 23, 928-935. https://doi.org/10.1016/j.foodhyd.2008.06.004

[23] Pourjavadi, A. and Mahdavinia, G.R. (2006) Superabsorbency, pH-Sensitivity and Swelling Kinetics of Partially Hydrolyzed Chitosan-g-poly(Acrylamide) Hydrogels. Turkish Journal of Chemistry, 30, 595-608.

[24] Clara, I., Lavanya, R. and Natchimuthu, N. (2016) pH and Temperature Responsive Hydrogels of Poly(2-acrylamido-2-methyl-1-propanesulfonic acid-co-methacrylic acid): Synthesis and Swelling Characteristics. Journal of Macromolecular Science, Part A; Pure and 
Applied Chemistry, 53, 492-499. https://doi.org/10.1080/10601325.2016.1189282

[25] Kim, S.J., Lee, K.J. and Kim, S.I. (2004) Swelling Behavior of Polyelectrolyte Complex Hydrogels Composed of Chitosan and Hyaluronic Acid. Journal of Applied Polymer Science, 93, 1097-1101. https://doi.org/10.1002/app.20560

\section{Submit or recommend next manuscript to SCIRP and we will provide best service} for you:

Accepting pre-submission inquiries through Email, Facebook, LinkedIn, Twitter, etc. A wide selection of journals (inclusive of 9 subjects, more than 200 journals)

Providing 24-hour high-quality service

User-friendly online submission system

Fair and swift peer-review system

Efficient typesetting and proofreading procedure

Display of the result of downloads and visits, as well as the number of cited articles

Maximum dissemination of your research work

Submit your manuscript at: http://papersubmission.scirp.org/

Or contact jbm@scirp.org 